
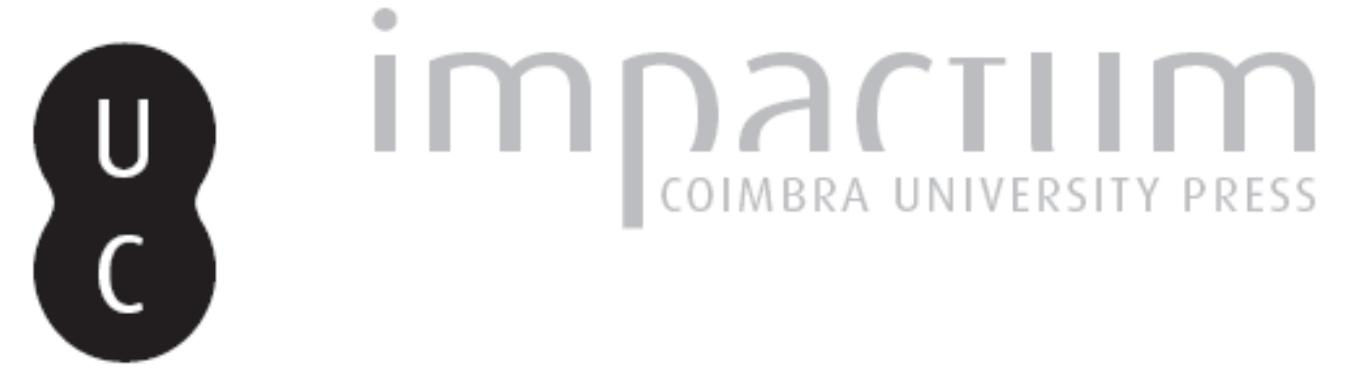

\title{
Os riscos na investigação científica realizada na Universidade de Coimbra
}

Autor(es): Rebelo, Fernando

Publicado por: Associação Portuguesa de Riscos, Prevenção e Segurança

URL persistente:

URI:http://hdl.handle.net/10316.2/39720

DOI:

DOI:http://dx.doi.org/10.14195/1647-7723_12_7

Accessed : $\quad$ 26-Apr-2023 08:46:29

A navegação consulta e descarregamento dos títulos inseridos nas Bibliotecas Digitais UC Digitalis, UC Pombalina e UC Impactum, pressupõem a aceitação plena e sem reservas dos Termos e Condições de Uso destas Bibliotecas Digitais, disponíveis em https://digitalis.uc.pt/pt-pt/termos.

Conforme exposto nos referidos Termos e Condições de Uso, o descarregamento de títulos de acesso restrito requer uma licença válida de autorização devendo o utilizador aceder ao(s) documento(s) a partir de um endereço de IP da instituição detentora da supramencionada licença.

Ao utilizador é apenas permitido o descarregamento para uso pessoal, pelo que o emprego do(s) título(s) descarregado(s) para outro fim, designadamente comercial, carece de autorização do respetivo autor ou editor da obra.

Na medida em que todas as obras da UC Digitalis se encontram protegidas pelo Código do Direito de Autor e Direitos Conexos e demais legislação aplicável, toda a cópia, parcial ou total, deste documento, nos casos em que é legalmente admitida, deverá conter ou fazer-se acompanhar por este aviso.

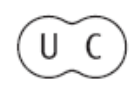




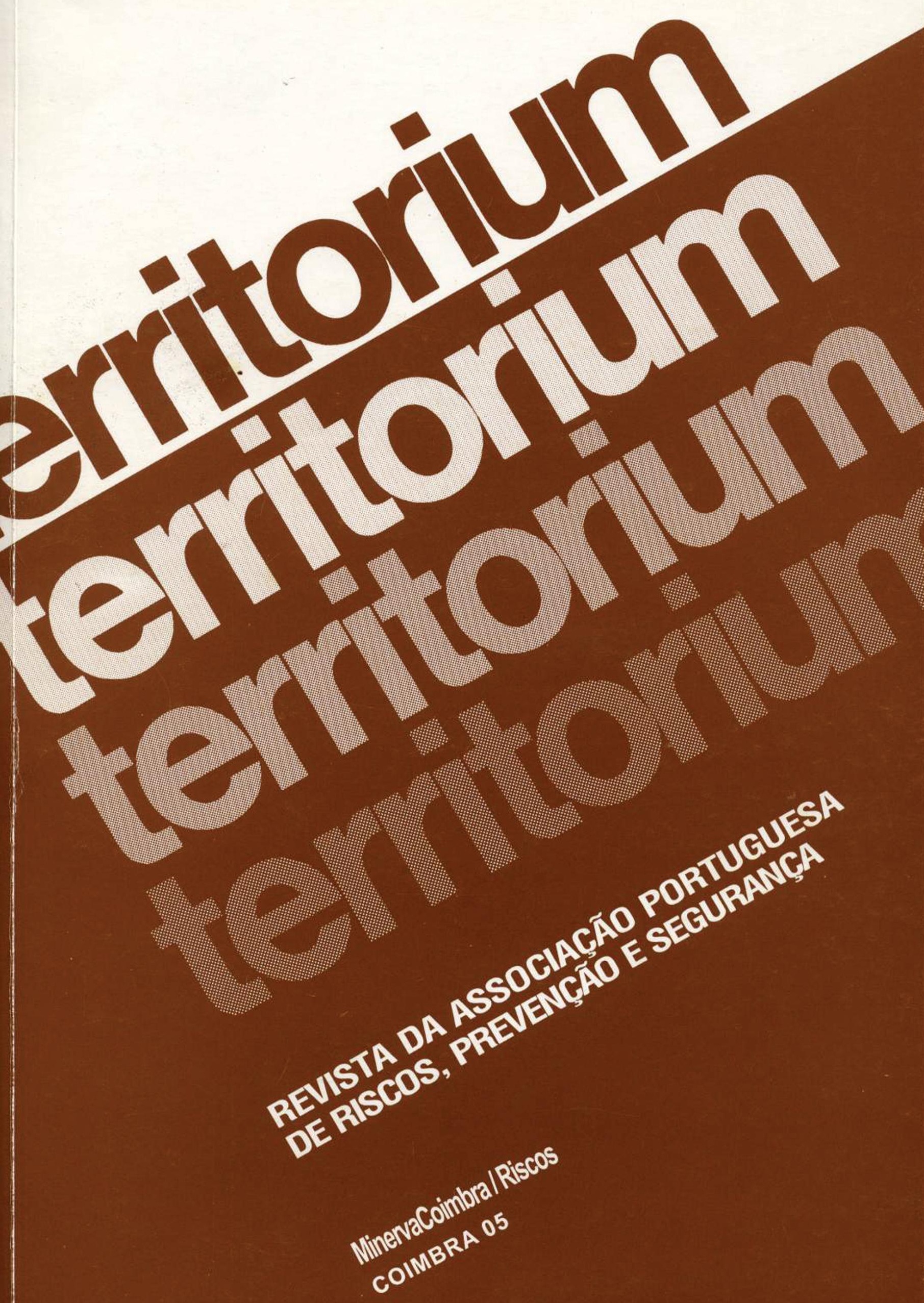




\title{
NOTAS, NOTÍCIAS E RECENSÕES
}

\section{Os Riscos na Investigação Científica realizada na Universidade de Coimbra*}

\author{
Fernando Rebelo
}

1. Orlando Ribeiro tinha apresentado e defendido a sua tese de doutoramento sobre a Serra da Arrábida, em 1936. Entre tantas outras coisas, referira processos erosivos nas vertentes e fenómenos de erosão e de deposição torrencial. Por essa altura, em Coimbra, Alfredo Fernandes Martins iniciara o seu curso de Ciências Geográficas; quatro anos depois, em 1940, na tese que teve de elaborar para completar a Licenciatura e a que deu o expressivo título de $O$ Esforço do Homem na Bacia do Mondego, a uma outra escala, não podia deixar de falar nas cheias e inundações do Mondego, tanto na perspectiva da sua compreensão, como na perspectiva dos problemas que elas foram criando ao Homem ao longo da História. Ainda ninguém falava em riscos naturais, mas Fernandes Martins foi pioneiro no seu estudo em Coimbra.

Quase 40 anos mais tarde, em 1978, já depois do meu doutoramento, assisti à passagem de uma frente fria bastante activa que originou severos prejuízos em toda a Região Centro. Percorri parte da área afectada entre Figueira da Foz e Aguieira, entre Espinho e Nazaré. E verifiquei como foram destruídos pinhais e eucaliptais por processos do tipo tornado entre Condeixa e Soure, como se desmoronaram tantas barreiras de estrada um pouco por todo o lado e, principalmente, como o mar avançou por avenidas marginais e ruas de muitas praias, chegando mesmo, nas proximidades da Costa Nova, a cortar o cordão litoral (e-a estrada) em três locais e a levar as suas águas até à Laguna de Aveiro. Dessas observações nasceu um trabalho que foi publicado na Finisterra, Revista Portuguesa de Geografia $(13,1978)$, lado a lado com outros estudos do género realizados noutras regiões do país sob a coordenação de Suzanne Daveau. Pela minha parte, o artigo intitulou-se "Os temporais de 25/26 de Fevereiro de 1978 no centro de Portugal".

A noção de crise, ou seja, de manifestação de riscos fora do controle do Homem, estava intrínseca nesses trabalhos. Tal como acontece em muitos incêndios florestais. Dos tempos de criança, nos inícios dos anos 50, tinha registado para sempre a observação de um incêndio florestal imenso na Serra da Agrela. Das aulas com Fernandes Martins tinha sabido de grandes incêndios florestais na Cordilheira

\footnotetext{
* Esta nota, embora devidamente actualizada, corresponde ao que, sob o mesmo título, foi apresentado no I Encontro Nacional de Riscos, Prevenção eSegurança realizado em Coimbra, no Auditório da Reitoria da Universidade, em 5 de Novembro de 2004.
}

Central por finais dos anos 50, início dos anos 60 . E sabia da sua convicção sobre os motivos que levariam as populações a ateá-los. Mas as notícias das emissoras de rádio ou dos jornais não se lhes referiam. Com a abertura política que se seguiu ao 25 de Abril de 1974, toda a gente passou a falar dos incêndios florestais, como se antes nunca tivessem acontecido. $\mathrm{E}$, pior do que isso, começaram a ser apontados responsáveis, que poderiam muito bem não o ter sido. Com os meus alunos de Climatogia, em 1976, realizei uma pesquisa sobre incêndios florestais no distrito de Coimbra, de que só vim a publicar os resultados em 1980, na Biblos, Revista da Faculdade de Letras da Universidade de Coimbra. Ainda praticamente não se falava de riscos e o título do trabalho é prova disso - "Condições de tempo favoráveis à ocorrência de incêndios florestais - análise de dados referentes a Julho e Agosto de 1975 na área de Coimbra".

Com todas as fragilidades que normalmente têm os primeiros trabalhos sobre qualquer matéria, este foi, apesar disso, o ponto de partida para uma investigação fecunda que se fez em Coimbra sobre riscos de incêndios florestais ao longo dos anos 80 e 90.

No IV Colóquio Ibérico de Geografia, organizado em 1986 pelo Instituto de Estudos Geográficos, Luciano Lourenço apresentou já uma comunicação muito importante sobre as "Consequências geográficas dos incêndios florestais nas serras de xisto do centro de Portugal". Tal como a subintitulou, era uma "Primeira abordagem". Mas noutras áreas da Geografia Física, tendo em vista o Colóquio Ibérico de 1986, também se trabalhou na perspectiva de aplicação aos riscos naturais. Com António Campar de Almeida, apresentei uma comunicação sobre cartas de declives, com Lúcio Cunha e Rochette Cordeiro, apresentei uma outra sobre ravinamentos e, com Nunes André, apresentei ainda outra sobre evolução de dunas.

2. Mas não eram só os geógrafos físicos que, em Coimbra, por meados dos anos 80 , trabalhavam em riscos. Na Faculdade de Ciências e Tecnologia, no Departamento de Engenharia Mecânia, mais precisamente no Centro de Mecânica de Fluidos, o Prof. Xavier Viegas, com a sua equipa, já investigava os fogos florestais. Em 1988, pôde mesmo organizar um notável encontro a que chamou I Jornadas Científicas sobre Incêndios Florestais. Convidado para presidir à mesa da $1^{\text {a }}$ sessão de trabalhos, tive o 
gosto de assistir à apresentação de uma comunicação assinada por Luciano Lourenço, Bento Gonçalves e H. Soares que se intitulava "Distribuição espacial dos incêndios florestais no Centro de Portugal, no período de 1983 a 1987. Contribuição para um mapa de risco de incêndios florestais". Eram os primórdios da utilização do conceito de risco, tomado então ainda como sinónimo de "hazard", de "aléa" ou, como dizem al guns dos nossos colegas brasileiros, de azar.

Estas Jornadas Científicas evoluíram rapidamente para Congressos Internacionais. A primeira International Conference on Forest Fires Research, organizada pelo Prof. Xavier Viegas, efectuou-se de 19 a 22 de Novembrode 1990 . Nela foram apresentadas muitas comunicações resultantes do trabalho de investigação levado a cabo em Coimbra, que se viram colocadas lado a lado com muitas mais vindas de outros núcleos de investigação, especialmente, do estrangeiro. Uma comunicação assinada por Zorro Gonçalvese Luciano Lourenço intitulava-se "Meteorological index of forest fire risk in the Portuguese mainland territory".

3. A investigação sobre riscos, efectuada no âmbito do Instituto de Estudos Geográficos, começava a ser conhecida em diversos meios. Por exemplo, ainda em 1990, Luciano Lourenço apresentou uma comunicação ao II Congresso Florestal Nacional, realizado no Porto, já com o sugestivo título de "Uma fórmula simples para o cálculo do risco meteorológico de incêndio na floresta de Portugal". E no ano seguinte, 1991, aqui mesmo em Coimbra, nos Cadernos Científicos sobre Incêndios Florestais, publicou o trabalho que intitulou "Uma fórmula expedita para determinar o índice meteorológico de risco de eclosão de fogos florestais em Portugal continental". Por outro lado, nesse mesmo ano, na Biblos $(67,1991)$ foi-me possível fazer uma pequena síntese da experiência que já tínhamos em Coimbra sobre riscos geomorfológicos no artigo "Geografia Física e Riscos Naturais. Alguns exemplos de riscos geomorfológicos em vertentes e arribas no domínio mediterrâneo", enquanto na Enciclopédia Temática - Portugal Moderno, no volume de Geografia, editado em Lisboa, publicava a síntese possível sobre o conjunto dos riscos ditos naturais - "Riscos Naturais" (p. 85-93 - por lapso, na $1^{\text {a }}$ edição, o trabalho aparece assinado com o nome de um colega da Universidade de Lisboa, que fazia a sua carreira universitária ligado a matérias bem diferentes).

Entretanto, os estudos da escola de Coimbra sobre incêndios florestais ganharam, em 1992, o estatuto que já mereciam no meio dos geógrafos portugueses quando Luciano Lourenço viu publicado na Finisterra $(27,1992)$ o seu trabalho "Avaliação do risco de incêndio nas matas e florestas em Portugal".
No ano seguinte, ele próprio organizou o IEncontro Pedagógico sobre Risco de Incêndio Florestal, tendo-me dado a honra de presidir à Comissão Organizadora e de fazer a intervenção de abertura, apresentando o Professor Ian Douglas, da Universidade de Manchester, que proferiu uma conferência sobre "Incêndios nas Florestas das Regiões Tropicais", na qual se debruçava, em especial, sobre o caso do Bornéu, que havia estudado. No ano seguinte, realizaram-se mais dois encontros deste tipo.

4. O ano de 1993 tinha começado sob a égide dos riscos. Aproveitando a vinda a Coimbra de um grupo de estudantes que frequentavam as aulas conducentes à obtenção do Diploma de Estudos Superiores Especializados em "Gestão Global dos Riscos", da Universidade de Paris I (Panthéon, Sorbonne), acompanhados por Lucien Faugères, organizei o I Encontro sobre Riscos Naturais Urbanos (2 de Fevereiro de 1993). Membro do staff docente desse curso, apresentei uma comunicação intitulada: "Hommes et érosion dans le centre et le nord du Portugal. Le cas du bassin du Mondego". Fi-lo em homenagem a Fernandes Martins, falecido dez anos antes (Dezembro de 1982), indubitavelmente o geógrafo que melhor soube compreender aquela relação no contex to da bacia do Mondego. A vinda dos estudantes e professores de Paris continuou a verificar-se até 2000, mas nunca mais a associei aos Encontros. Em separado da semana de estágio de campo sobre riscos naturais, sociais e tecnológicos que lhes ministrava, os Encontros sobre Riscos Naturais, que chegaram a atrair mais de 450 participantes, continuaram a realizarse até Dezembro de 2003, totalizando o número de 10. Sempre neles foram àpresentados trabalhos de investigação elaborados por colegas de Coimbra ou de outras Universidades, com ligações ao nosso grupo, em pé de igualdade com trabalhos trazidos por vários nomes grandes da Geografia Física europeia.

5. Oreconhecimento da importância da investigação científica, inter multidisciplinar, realizada em Coimbra sobre incêndios florestais levou a que em 15 de Abril de 1994 tivesse sido encarregado de organizar dois debates no âmbito da Presidência Aberta sobre Ambiente, efectuada pelo Presidente da República, Dr. Mário Soares. Assim, no Aeródromo da Lousã, falou-se sobre "Fogos Florestais" - fiz a palestra introdutória e moderei o debate - e em Coimbra, no Auditório da Faculdade de Economia, falou-se sobre "O futuro da floresta portuguesa e o seu enquadramento internacional" - fiz também a palestra introdutória e co-moderei o debate, juntamente com Henrique Soares de Albergaria.

Por essa altura, tínhamos em desenvolvimento um Projecto de Investigação sobre Risco de Incêndios 
Florestais, com financiamento obtido através de um protocolo envolvendo a JNICT (Junta Nacional de Investigação Científica e Tecnológica) e a CNEFF (Comissão Nacional Especializada de Fogos Florestais). Fez, portanto, sentido, para nós, que, em 1995, se realizassem as 1 as Jornadas de Investigação Científica e Tecnológica Aplicada a Incêndios Florestais. A organização foi da JNICT e da CNEFF e realizaram-se em Coimbra, no Auditório da Comissão de Coordenação da Região Centro. Pela nossa parte, Luciano Lourenço apresentou o projecto, que se intitulava "Proposição de uma fórmula capaz de determinar o risco integrado de incêndios florestais". Um novo Projecto, apresentado às mesmas entidades no ano anterior, estava já então pronto para avançar: "Determinação da tendência diária do índice de risco de incêndio florestal durante a "época de fogos" de 1995". Este foi indubitavelmente um dos Projectos de Investigação Aplicada mais importantes que se desenvolveram em Portugal na área dos fogos florestais - diariamente, os geógrafos, sob a orientação de Luciano Lourenço, davam a conhecer o risco de incêndio a quem tinha por missão combatê-los o mais depressa possível se se manifestassem, acorrendo em situações de perigo, ou seja, em situações facilmente controláveis, evitando que se passasse a situações de crise, ou seja, a situações que fugissem ao controle. Mas, do mesmo modo, outras entidades, por exemplo, policiais, tinham acesso a esses documentos diários. Ainda nesse ano, foi proposto, e também aprovado através de idêntico protocolo entre a JNICT e a CNEFF, um terceiro Projecto intitulado: "Investigação de causas conducentes à ocorrência e propagação do fogo florestal em quatro concelhos-tipo da região centro do país". Decorreu ao longo do ano seguinte.

Em 1995, estivemos igualmente presentes, os dois, no Seminário Internacional sobre Fogos Florestais, organizado pela Associação Nacional de Municípios Portugueses (ANMP), em Vilamoura. Para enquadrar os incêndios de um modo mais amplamente geográfico, falei sobre a floresta no mundo e os grandes incêndios florestais.

6. Uma das maiores preocupações dos investigadores europeus ligados aos riscos era, desde os fins dos anos 80 , a organização de um thesaurus que servisse de base à constituição de uma nova ciência, a Cindínica (talvez melhor, a Cindinicologia) ou de várias, as Ciências Cindínicas, como preferia GeorgesYves Kervern. A teoria discutia-se em Seminários que se efectuavam um pouco por todos os países europeus. Pessoalmente, estive presente em alguns, como por exemplo, na Holanda (Midelburgo) e em França (Paris e Ilha de Frioul). Mas também tivemos o nosso Séminaire de Coimbra sur la Gestion des Risques et des Crises. Organizado pelo Grupo Europeu para o Estudo dos Riscos e das Crises (GEERC), no âmbito do Programa ERASMUS, o Seminário de Coimbra reuniu, em 1996, mais de uma dezena de professores franceses no Salão da Reitoria da Universidade de Coimbra. Entre eles estavam Lucien Faugères e George Yves Kervern, que, como logo me disseram, ficaram impressionados com o trabalho desenvolvido na área dos incêndios florestais pelas equipas de Xavier Viegas e de Luciano Lourenço. No ano seguinte (1997), no Séminaire du Frioul sur la Gestion des Risques et des Crises, professores franceses e holandeses ficaram igualmente impressionados com a lista dos mais recentes trabalhos, eleborados em Coimbra, sobre riscos naturais, que apresentei na comunicação intitulada "Géographie Physique et Risques à Coimbra - années 90".

7. Os incêndios florestais e a sua prevenção continuaram sempre a ocupar um lugar privilegiado nas investigações realizadas no Instituto de Estudos Geográficos. Em 1997, e em ligação com um dos mais interessantes projectos realizados no nosso país sobre esta matéria, Luciano Lourenço, no âmbito do entretanto formado NICIF (Núcleo de Investigação Científica de Incêndios Florestais, da Faculdade de Letras da Universidade de Coimbra), organizou as I Jornadas Nacionais PROSEPE, Floresta Viva. Apresentei uma comunicação intitulada "Floresta e Turismo. Alguns exemplos portugueses com interesse turístico particularmente no Centro de Portugal". Por muito estranho que pareça, tratava-se de dar mais uma pista para atingir a meta da prevenção dos fogos florestais. O PROSEPE (Projecto de Sensibilização da População Escolar) movimentou muita gente em todo o país, em especial professores de várias áreas científicas, que depois multiplicavam a mensagem da prevenção aos seus alunos. Estes levavam a mensagem para os familiares e amigos. Nos anos seguintes, realizaram-se mais oito jornadas. Uma delas teve uma assistência superior a mil participantes e realizou-se emFátima. Através do NICIF, a Universidade de Coimbra foi pioneira, também, na pesquisa de metodologias para levar aos jovens o amor pela floresta como forma primeira da prevenção de incêndios florestais.

8. O reconhecimento pelo nosso trabalho é sempre algo de gratificante. E isso sente-se nos convites que nos fazem para proferir conferências sobre a temática dos riscos. Entre muitas, que Luciano Lourenço e eu fizemos pelo país e pelo estrangeiro, na segunda metade dos anos 90, destacarei, pelo significado que tiveram, apenas duas - a que proferi em Paris, em 1998, no Anfiteatro Bachelard, do edifício histórico da Sorbonne, sobre o caso concreto das inundações rápidas no sul de Portugal no Outono de 1997, e a que, em 1999, proferi em sessão ordinária da Academia 
das Ciências de Lisboa, intitulada "A Geografia e os estudos de riscos. O exemplo da Geografia Física em Coimbra". No entanto, dois anos depois (2001), não deixou, também de ser reconhecimento pelo trabalho realizado no nosso Grupo, o convite que recebi para moderar o Terceiro Painel, "Investigação Científica Aplicada", e para presidir e moderar a Sessão Plenária da Conferência Nacional sobre Prevenção e Investigação de Incêndios Florestais, organizada pela CNEFF, emÉvora, tal como, em 2002, o convite para apresentar uma comunicação sobre a legislação portuguesa sobre riscos naturais ao Colloque International Risques Naturels et Aménagementen Europe, organizado pela Universidade de Paris X (Nanterre) e pelo Ministério Francês doEquipamento, no Auditório da Grande Arche de La Defense, do qual foi, entretanto, publicado um livro com o título Risques Naturels et Aménagement en Europe (Paris, Armand Colin, 2004, 254 p.).

Já em 2005, considerei também muito gratificante o convite que me foi dirigido pelo Prof. Carlos Guedes Soares para apresentar uma comunicação sobre riscos naturais no $1^{\circ}$ Congresso de Riscos, Segurança e Fiabilidade, promovido pela Secção Portuguesa da ESRA (European Safety and Reliability Association), no Instituto Superior Técnico.

9. Muitos trabalhos sobre riscos naturais foram publicados em Coimbra, principalmente, em actas de Congressos, Jornadas ou Encontros. Uma colectânea minha, de estudos relacionados com riscos, foi editada pela Imprensa da Universidade de Coimbra em 2001 - Riscos Naturais e Acção Antrópica. Uma segunda edição saiu em 2003. Na Faculdade de Letras foram lançadas, em 2004, duas colectâneas de estudos sobre riscos de Luciano Lourenço, a que logo se seguiram mais três. De igual modo, houve teses de Mestrado em Geografia Física sobre incêndios florestais, sobre movimentação de areias em dunas, sobre movimentos de vertentes, sobre inundações, sobre cartografia, etc. Em 2004, foi também apresentada e defendida uma tese de Mestrado em Engenharia Civil sobre planeamento urbano e protecção civil, que se referia a riscos geomorfológicos na cidade de Coimbra.

Paralelamente, desde meados dos anos 90 , colegas da área da Geografia Física da Faculdade de Letras da Universidade do Porto, em ligação connosco, desenvolveram importantes trabalhos de investigação sobre riscos, que apresentaram publicamente na sua Universidade e na nossa, sob a forma de comunicações, artigos e capítulos de livros.

No entanto, com nome sugerido por um dos colegas do Porto que mais trabalharam connosco, António de Sousa Pedrosa, foi a revista Territorium, editada pela MinervaCoimbra, que, desde 1994, se impôs na área dos riscos, em particular, naturais, divulgando trabalhos efectuados na Universidade de Coimbra, mas também noutras Universidades ou instituições não universitárias do país e do estrangeiro. Considerada a única revista de riscos existente em Portugal e uma das poucas existentes no mundo, ela publicou artigos feitos a partir de comunicações apresentadas nos Encontros sobre Riscos Naturais, bem como outros que nos eram enviados e que nos pareciam oportunos e de qualidade. Analisando os seus dez primeiros números, que corresponderam à primeira série, em que tinha como subtítulo "Revista de Geografia Física Aplicada no Ordenamento do Território e Gestão de Riscos Naturais", verificamos que foram publicados 65 artigos por 38 autores (considerando apenas o nome do autor individual ou do primeiro autor quando se trate de trabalhos colectivos). Destes 38 autores, 27 são portugueses e 11 estrangeiros. Dos 27 portugueses predominam os geógrafos (22), onde encontramos quase todos os colegas da área de Geografia Física do Instituto de Estudos Geográficos da Universidade de Coimbra (6), mas também vários colegas das Universidades do Porto (7), de Lisboa (2), de Aveiro (2), Nova de Lisboa (1), do Minho (1) e da Madeira (1), ao lado de geógrafos investigadores não universitários (2); mas escreveram artigos também 3 engenheiros (um dos quais da Universidade de Coimbra), 1 geólogo (da Universidade de Coimbra)e 1 sociólogo. Quanto aos 11 estrangeiros, 9 são geógrafos (4 brasileiros, 3 espanhóis, 1 inglês e 1 francês), 1 é geólogo (cabo verdiano) e 1 biólogo (brasileiro). Foram, igualmente, publicadas 47 notas, notícias ou recensões por apenas 9 autores nacionais, 8 dos quais geógrafos (4 do Instituto de Estudos Geográficos da Universidade de Coimbra, 1 da Universidade do Porto, 1 daUniversidade de Aveiro e 2 não universitários) e 1 engenheiro (da Universidade de Coimbra).

O $11^{\circ}$ número da Territorium, sendo o primeiro da nova série que tem como subtítulo "Revista da Associação Portuguesa de Riscos, Prevenção e Segurança, publicou 4 arțigos $-o 1^{\circ}$ e $04^{\circ}$ da autoria de geógrafos espanhóis, respectivamente, das Universidades de Huelva e de Salamanca, o $2^{\circ}$ da autoria de dois geógrafos brasileiros, da Universidade do Estado da Bahia, e o $3^{\circ}$ da autoria de um geógrafo do nosso Instituto. Como sempre, publicou, igualmente, várias notas, notícias e recensões. No entanto, desta vez, terminava com um apêndice - os Estatutos da Riscos, Associação Portuguesa de Riscos, Prevenção e Segurança.. Efectivamente, alguns de nós, que trabalhamos nesta área desde há muito tempo, juntámo-nos a outros que também têm percursos semelhantes, universitários ou não universitários, e nos finais de 2003 decidimos organizar esta Associação Sem Fins Lucrativos, tendo em vista, antes de mais, dar uma contribuição importante para a consciencialização 
dos riscos, a percepção dos perigos e a gestão das crises no nosso país. A Territorium, continuando a ser publicada pela MinervaCoimbra, já é a revista da Associação Riscos que organizou, por altura do seu lançamento, o I Encontro Nacional de Riscos.
Opresente número da Territorium, $\mathrm{o} 12^{\circ}$, apresenta 3 artigos de engenheiros, 2 de geógrafos, e 1 de um sociólogo, mantendo, assim, a abertura científica que a vem caracterizando.

\section{O Tsunami do Índico. 26 de Dezembro de 2004, um dia negro para a história do mundo*}

\section{Fernando Rebelo}

1. O dia 26 de Dezembro de 2004 irá ficar na memória de milhões de pessoas e será lembrado por numerosos cientistas em todo o mundo. Um tsunami violento, originado por um terramoto com epicentro ao largo da ilha de Sumatra, matou, feriu e assustou gente de aldeias piscatórias, praias, centros turísticos e cidades litorais, sem distinguir entre ricos e pobres. Ondas gigantescas chegaram rapidamente às costas mais próximas do epicentro, na Indonésia e na Tailândia e, logo a seguir, às do Sri Lanka e da Índia. Mantendo a sua força destruidora, atravessaram todo o Oceano Índico e atingiram parte da África oriental. Já com pouca importância, ainda atravessaram o Atlântico e o Pacífico tendo sido registadas, por exemplo, no Brasil e no Japão.

Porque morreram mais de 300000 pessoas com este tsunami? Em 1836, tinha-se verificado um tsunami semelhante quando da explosão do Krakatoa. As costas atingidas terão sido as mesmas. Mas se formos ver os registos das maiores catástrofes mundiais deste tipo, verificamos que, para alguns autores, houve, apenas, 33000 mortos, enquanto para outros poderão ter sido 36000 .

$\mathrm{Na}$ verdade, o risco resulta da consideração de dois factores - o processo em si e a vulnerabilidade. Se a força do processo foi praticamente igual, a vulnerabilidade, que já era grande no século XIX, devido à existência de algumas cidades litorais e muitos portos de pescadores, era, agora, muitíssimo maior pelo crescimento desmesurado dessas cidades e desses portos, atendendo ao elevado crescimento demográfico das populações asiáticas e africanas. Mas terá, ainda, de juntar-se a recente criação de numerosas áreas turísticas, por vezes, concentradas em cidades, muitas vezes, dispersas pelas costas ou porilhas com paisagens mais ou menos paradisíacas. A população exposta ao risco natural era demasiada e, à parte os turistas, na sua esmagadora maioria, muito pobre. As suas habitações nãoestavam preparadas

* Texto publicado na revista Rua Larga. Revista da Reitoria da Universidade de Coimbra, 9, 2005, p. 47-48. para enfrentar um forte ataque das águas do mar. Em regra, baixas e construídas em madeira, taipa ou, apenas, argila, as casas não podiam resistir à violência das águas do mar. Depois, o material que serviu para a construção foi levado pelas águas, em suspensão ou emflutuação, aumentandoa sua violência destruidora ao longo dos espaços percorridos para o interior e que tanto podiam ser vales de rios ou campos de arroz, como podiam ser ruas de cidades. As casas de pedra e de cimento, com vários andares, tal como alguns grandes templos, que não caíram com o terramoto, serviram de refúgio nas partes altas.

Nunca o risco de tsunami se tinha manifestado como tão grande catástrofe. 100000 mortos era o máximo registado no Japão, em 1703 (ZEBROWSKI, 1997).

2. Portugal tem memória de vários terramotos seguidos de tsunamis. Comemoram-se este ano os 250 anos daquele que ficou conhecido como terramoto de Lisboa de 1 de Novembro de 1755. Depois do forte tremor de terra que tanta destruição causou na cidade, mas igualmente em grande parte do país, com especial incidência, na Bacia do Tejo e no Algarve, chegou um tsunami que poderá ter matado ainda mais pessoas do que o desabamento de casas e igrejas. Em 28 de Fevereiro de 1969, após um sismo que teve o seu epicentro na mesma área do de 1755 , ou seja, na área do Banco de Gorringe, a SW do Cabo de São Vicente, também se verificou um tsunami, mas de fraca importância, que não causou danos. Muito mais recente foi o susto vivido por milhares de banhistas que se encontravam no Algarve em Agosto de 1999, quando alguém se lembrou de interpretar como tsunami uma linha paralela ao horizonte, muito próxima do nível do mar, que se via das praias e que parecia ser uma onda em início de rebentação. $\mathrm{O}$ aviso foi lançado e enquanto uns fugiam, outros aproximaram-se para ver... Pedi, na altura a Antunes do Carmo, engenheiro civil e professor da Faculdade de Ciências e Tecnologia da Universidade de Coimbra, para dizer aos geógrafos o que é na realidade um tsunami e explicar, assim, os 